\title{
COMPARATIVE PERFORMANCE OF CARRIER BASED PWM SCHEMES FOR SINGLE STAR BRIDGE CELL (SSBC) CONFIGURATION
}

\author{
K.B.V.S.R. SUBRAHMANYAM ${ }^{1}$, RAM DESHMUKH ${ }^{2}$, S. SAIKIRAN ${ }^{3} \&$ M. SREEKAR REDDY ${ }^{4}$ \\ ${ }^{I}$ Associate Professor, EEE Department, S R Engineering College, Ananthsagar, Warangal, Telangana, India \\ ${ }^{2}$ Professor, EEE Department, S R Engineering College, Ananthsagar, Warangal, Telangana, India \\ ${ }^{3,4}$ Students, EEE Department, S R Engineering College, Ananthsagar, Warangal, Telangana, India
}

A reliable and economical power converter is a pre-requisite for various commercial and industrial applications such as Energy storage, Grid connected-PV/Renewable system, Adjustable speed drives, Power quality (custom power devices), HVDC and Transportation applications. Further with the development/fabrication of advanced self-communicating devices, Multilevel Inverters (MLIs) emerged as reliable and effective power converter for applications of high power. The popular modular configuration is the Cascaded H-Bridge MLI in the present era. On the other hand, among the various control techniques reported for MLIs, Sinusoidal PMW techniques are most popular and easier practiced techniques. As MLIs and SPWM are being very popular and tremendously used in research, enlightenment on their design, implementation and control with various Sinusoidal PWM techniques is deriving key of the current times. Hence in this paper, implementation of CHB-MLI for generalized level, with various carrier based PWM (LSPWM-IPD, OPD, APD, AND PSPWM) techniques is presented, and converter phase and line voltage harmonic performance with various carrier arrangements is evaluated for variation in level numbers and modulation index of amplitude (ma). Also, the effect of frequency modulation index on harmonic spectrum is discussed in detail, and obtained results are validates on the MATLAB.

KEYWORDS: PWM (Pulse Width Modulation), MLI, CHB (Cascaded H-Bridge), Level Shifted PWM (LSPWM), APOD (Alternate Phase Opposition Disposition), IPOD (In Phase Opposition Disposition), OPD (Opposite Phase Disposition), THD (Total Harmonic Distortion)
\end{abstract}

Received: Jun 06, 2020; Accepted: Jun 26, 2020; Published: Aug 24, 2020; Paper Id.: IJMPERDJUN2020863

\section{INTRODUCTION}

The recent requirement of High power and High voltages increased the demand for High power converters, some recent applications like Battery storage systems, Power quality etc., requires efficient high-power converters. There are converters $\mathrm{AC}-\mathrm{AC}$ and converters DC-AC. In the case of converters DC-AC, the main purpose is to convert DC voltage to a $\mathrm{AC}$ voltage variable and converters DC-AC are 3 types namely Two-level inverters, Multipulse converters, Multilevel inverters. Two-level inverter produces different voltages, i.e., two voltages to the load, for example if we give $1 \mathrm{v}$ as input, it gives divide it into two halves and produces $+1 / 2$ and $-1 / 2$ as output. Even though this method is good, it raises some disadvantages like high THD in the output, dv/dt stress is high in two-level inverter, due to these disadvantages it has limited applications. In Multipulse converters there is an inter connection of multiple two-level inverters, in this case harmonics gets cancelled by two inverters.

In Multipulse inverter several three phase two-level inverters units are interconnected and uses 
transformers as magnetic interfaces for achieving high power rating and harmonic neutralization.

As addressed in [1] article, the author classified the Multilevel Inverters into three different types, they are MLI of Diode Clamped, Capacitor Clamped, Cascaded H-bridge. Diode Clamped inverter transfers voltage in a limited amount, and on other electrical devices, this results in stress reduction, where a Flying Capacitor's voltage at the output is input DC voltage half, are the main drawbacks of these type of inverters. In a Cascaded H-Bridge MLI there are switches and capacitors used in less number in each level. The H-Bridge is a combination of these components. In this CHB MLI, for each H-Bridge separate input DC voltage is provided, the main advantage with this type of inverters is, it requires less components like switching devices, that is why CHB MLI is preferable than the other MLI's. CHB type eliminates the usage of transformers.

In an MLI, harmonic elimination is the most important one, As addressed in [2] article, the author represented the various PWM strategies for a CHB MLI, as we know several MLI techniques of modulation and Multi-Carrier Pulse Width Modulation (MCPWM) method is used widely, because of its easy implementation for lower voltages, MCPWM method has two different methods of modulations, they are Level Shifted PWM (LSPWM) and Phase Shifted PWM (PS-PWM) methods. LSPWM is categorized into Alternative Phase Opposition Disposition (APOD) [1], Phase Opposition Disposition (POD) [2], In Phase Opposition Disposition (IPOD) [3]. This paper presents the comparative analysis of Level Shifted PWM techniques for CHBMLI. The results for simulation are obtained for9-level, 7-level, 5-level [5] [6] CHBMLI's based on LSPWM (APOD, POD, IPOD) modulation techniques. Simulation result of LSPWM (APOD, POD, IPOD) techniques are simulated in MATLAB/Simulink tool box.

\section{MODULATION TECHNIQUES OF CHB-MLI}

There are many modulation strategies but Carrier based PWM technique is more popular because of its easy implementation for low voltage modules, Carrier based PWM technique is of two types, they are:

- Phase-Shifted Multicarrier Modulation

- Level-Shifted Multicarrier Modulation

\section{Phase Shifted Multicarrier Modulation}

In an MLI with voltage levels $\mathrm{m}$, it requires (m-1) number of carriers of triangular in nature, with the same amplitude and frequency, and shifting of phase of the two carrier waves adjacent in between exists.

\section{Level Shifted Multicarrier Modulation}

In this type, m-level MLI has (m-1) number of carriers of triangular in nature, with the same amplitude and frequency, the carrier waves are disposed in vertical manner, and so the occupied bands are continuous. THD performance of this modulation is better than Phase shifted multicarrier modulation.

The various types of this modulation strategies are

- APOD,

- POD,

- IPOD 
Alternate Phase Opposite Disposition (APOD)

Here, each carrier wave is out of phase with respect to its carrier next wave by 180 degrees as in [1].

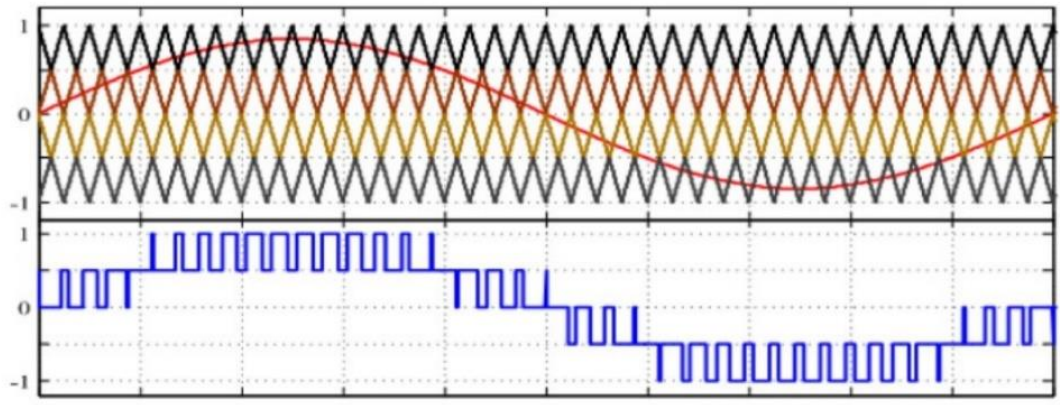

Figure 1: APOD PWM Technique Representation.

Phase Opposition Disposition (POD)

Here, all the carrier waves are in phase above the zero reference point and all the carrier waves are $180^{\circ}$ out of phase below the zero point as in [2].

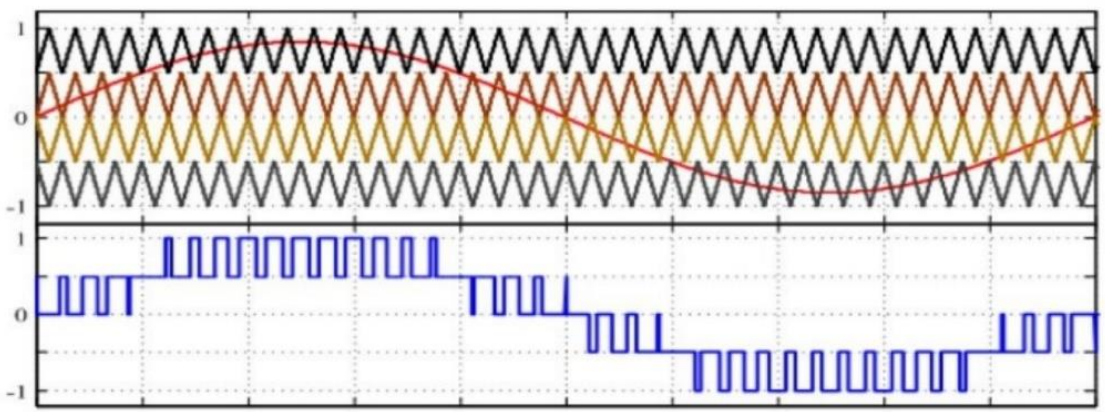

Figure 2: POD PWM Technique Representation.

In Phase Opposition Disposition (IPOD)

Here, all the carrier waves are in phase with each other as in [3].

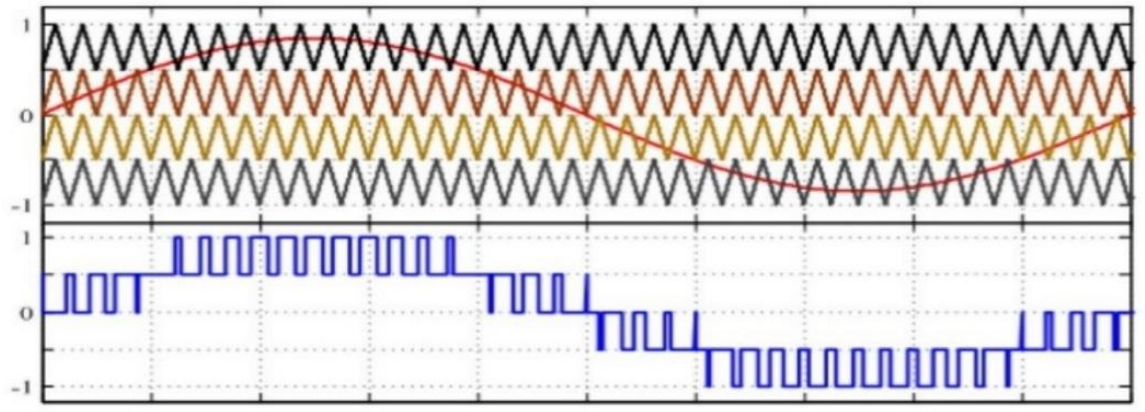

Figure 3: IPOD PWM Technique Representation.

\section{PROPOSED METHODOLOGY FOR CASCADED H-BRIDGE MULTI-LVEL INVERTER}

\section{Proposed Methodology}

The below shown is the circuit diagram of CHB MLI 5-level with DC sources of two and eight switches. 


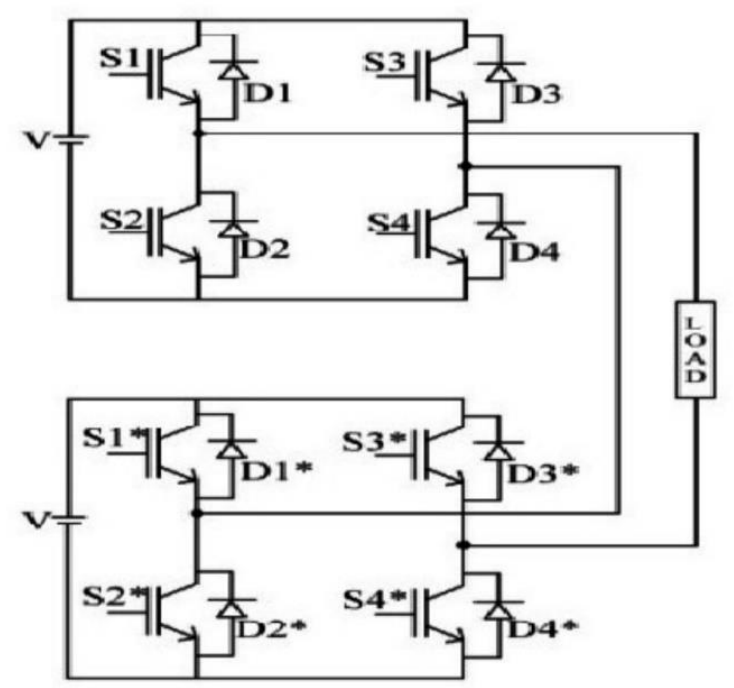

Figure 4: CHB MLI 5-Level.

Table 1: Switching States of CHB MLI 5-Level

\begin{tabular}{|c|c|}
\hline Switches Turn On & $\begin{array}{c}\text { Voltage } \\
\text { Level }\end{array}$ \\
\hline $\mathrm{S} 1, \mathrm{~S} 2$ & $+\mathrm{Vdc}$ \\
\hline $\mathrm{S} 1, \mathrm{~S} 2, \mathrm{~S} 5, \mathrm{~S} 6$ & $+2 \mathrm{Vdc}$ \\
\hline $\mathrm{S} 4, \mathrm{D} 2, \mathrm{~S} 8, \mathrm{D} 6$ & 0 \\
\hline $\mathrm{S} 3, \mathrm{~S} 4$ & $-\mathrm{Vdc}$ \\
\hline $\mathrm{S} 3, \mathrm{~S} 4, \mathrm{~S} 7, \mathrm{~S} 8$ & $-2 \mathrm{Vdc}$ \\
\hline
\end{tabular}

Similarly, the PWM topology is applied for 7-level \& 9-levels (Single phase and Three phase)

\section{Merits of CHB MLI's}

The main Merits of CHB ML's are

- Common Voltage Mode: CHB MLI's produce Common voltage which reduces the stress on the electrical devices like motors etc., and do not damage the device.

- Input Current: CHB MLI's draws input current with low distortion, which is the main advantage.

- Switching Frequency: When there is less switching frequency, the switching losses are less so that the efficiency will be increased. CHB MLI's operates at high and low switching frequencies.

- $\quad$ Reduced THD: In CHB MLI's the Selective Harmonic Elimination with multilevel topologies ultimately results in less THD level, we can obtain much smoothed output without using filters.

- $\quad$ Used in designing and Modelling of a PV system[7] [8] 


\section{RESULTS AND DISCUSSIONS}

\section{Results and Analysis of Simulation}

Simulation of 9-level, 7-level,5-level CHB MLI is carried out using MATLAB. The following are the simulation results.

Case 1: CHBMLI 5-level Single phase with OPD PWM strategy.

5-level CHBMLI Single phase with OPD PWM strategy is simulated as in [5].

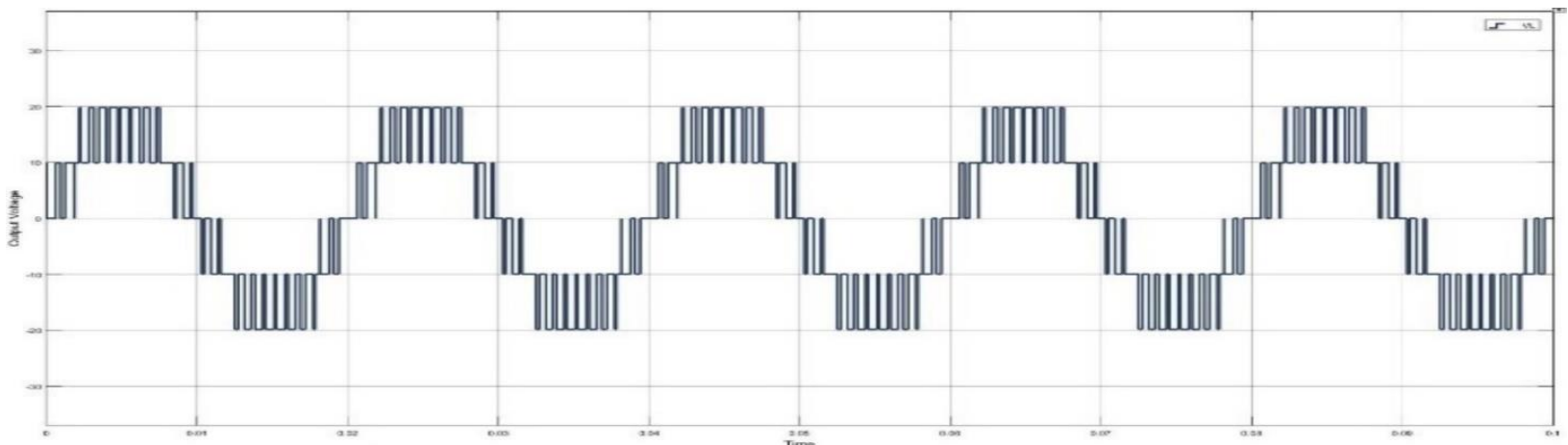

Figure 5: Output Voltages of 1 Phase 5-Level CHB MLI with OPD PWM Technique.

Case 2:7-level CHBMLI Single phase with IPD PWM technique.

7-level CHBMLI Single phase with IPD PWM strategy is simulated as in [6].

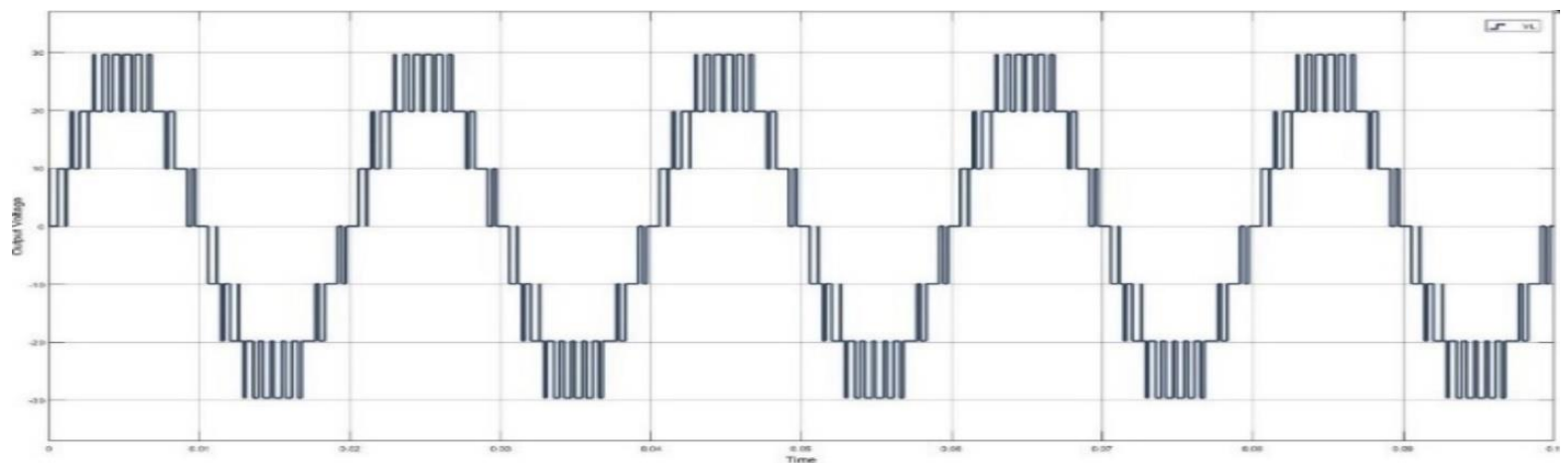

Figure 6: Output Voltages of 1 -Phase CHB MLI 7-Level with IPD PWM Technique.

Case 3:9-level CHBMLI Single phase with APD PWM technique.

9-level CHBMLI Single phase with APD PWM strategy is simulated as in [7].

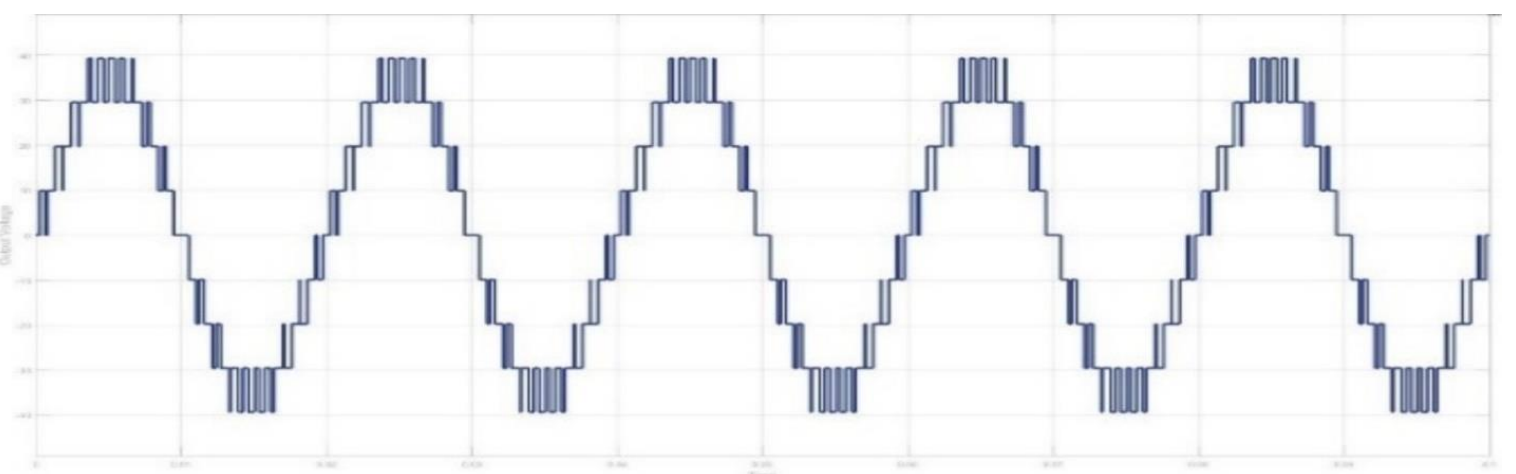

Figure 7: Output Voltages of 1- Phase CHB MLI 9-Level with APD PWM Technique. 
Case 4: 7-level CHBMLI Three phase with IPD PWM technique

7-level CHBMLI Three phase with IPD PWM technique is simulated as in [8].
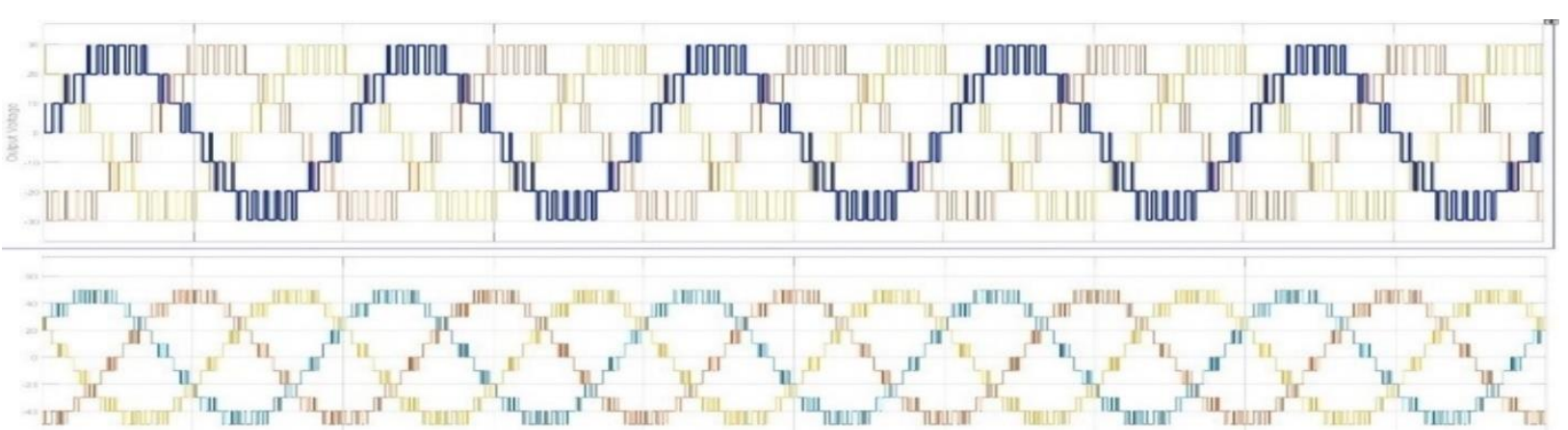

Figure 8: Output Voltages of 3- Phase CHBMLI 7-Level with IPD PWM Technique.

Case 5: CHBMLI 9-level3- phase with APD PWM strategy.

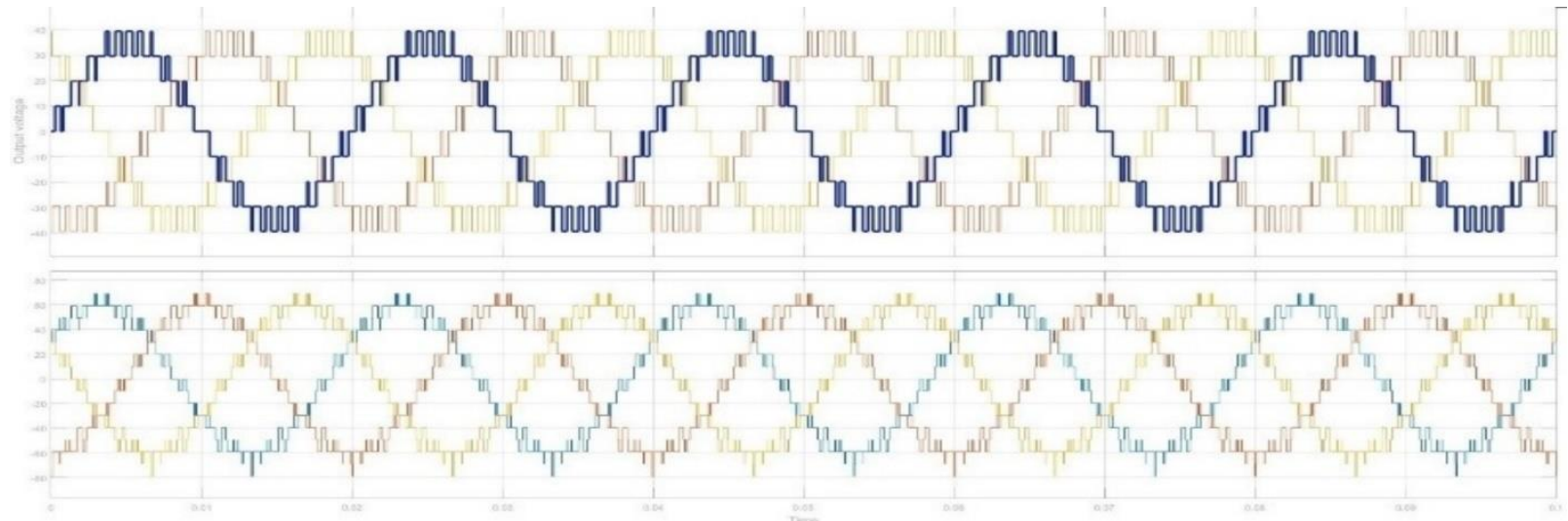

Figure 9: Output Voltages of CHBMLI 9-Level 3- Phase with APD PWM Technique.

\section{Analysis of THD Performances}

The THD performance and analysis for Three phase 7-level\&9-level CHB MLI's at different frequencies \& different values of ma at APD, IPD, OPD PWM techniques are observed and tabulated as shown below.

Table 2: CHB MLI7-Level Three Phase, Frequency=900 Hz

\begin{tabular}{|c|c|c|c|c|c|c|}
\hline \multirow{2}{*}{ ma } & \multicolumn{2}{|c|}{ APDPWM } & \multicolumn{2}{c|}{ OPDPWM } & \multicolumn{2}{c|}{ IPDPWM } \\
\cline { 2 - 7 } & PHTHD & LTHD & PTHD & LTHD & PTHD & LTHD \\
\hline 0.5 & 0.3986 & 0.2848 & 0.3914 & 0.3692 & 0.3987 & 0.235 \\
\hline 0.6 & 0.3199 & 0.2739 & 0.3273 & 0.2945 & 0.3332 & 0.1748 \\
\hline 0.7 & 0.2279 & 0.2123 & 0.2298 & 0.1751 & 0.2481 & 0.163 \\
\hline 0.8 & 0.2335 & 0.1793 & 0.2281 & 0.2086 & 0.2435 & 0.1255 \\
\hline 0.9 & 0.2281 & 0.1821 & 0.2 & 0.1906 & 0.2194 & 0.1324 \\
\hline 1.0 & 0.1682 & 0.1421 & 0.164 & 0.1394 & 0.1682 & 0.1033 \\
\hline
\end{tabular}

From the above table, for a Cascaded H-bridge Multilevel inverter seven level three phase with frequency 900 hertz, it is noticed that when the modulation index amplitude (ma) is increasing, the phase and line THD's are decreasing and it is observed that IPD PWM technique was more efficient when compared with other two PWM techniques, the graph [11] indicates the changes in THD with respect to the increase in amplitude modulation index. 
Table 3: Three Phase 9-Level CHB MLI, Frequency=1350 Hz

\begin{tabular}{|c|c|c|c|c|c|c|}
\hline \multirow{2}{*}{ ma } & \multicolumn{2}{|c|}{ APDPWM } & \multicolumn{2}{c|}{ OPDPWM } & \multicolumn{2}{c|}{ IPDPWM } \\
\cline { 2 - 7 } & PHTHD & LTHD & PTHD & LTHD & PTHD & LTHD \\
\hline 0.5 & 0.2692 & 0.2551 & 0.2692 & 0.2163 & 0.2691 & 0.1727 \\
\hline 0.6 & 0.243 & 0.1971 & 0.243 & 0.2204 & 0.2429 & 0.1308 \\
\hline 0.7 & 0.2103 & 0.1718 & $0 . .2106$ & 0.191 & 0.2105 & 0.1206 \\
\hline 0.8 & 0.1714 & 0.1364 & 0.1714 & 0.1411 & 0.1713 & 0.1057 \\
\hline 0.9 & 0.1657 & 0.1199 & 0.1657 & 0.1524 & 0.1657 & 0.08706 \\
\hline 1.0 & 0.1369 & 0.1218 & 0.1369 & 0.1158 & 0.1364 & 0.08305 \\
\hline
\end{tabular}

In the above comparison it is seen that when amplitude modulation index increases the THD decreases, this was shown in [11] and the FFT analysis is shown in [13], it is noticed that when the level of voltage increases the THD decreases, for a three phase system it is seen that IPD PWM technique is efficient.

\section{Graphical Representation of THD Performance of 3 Phase CHB ML}

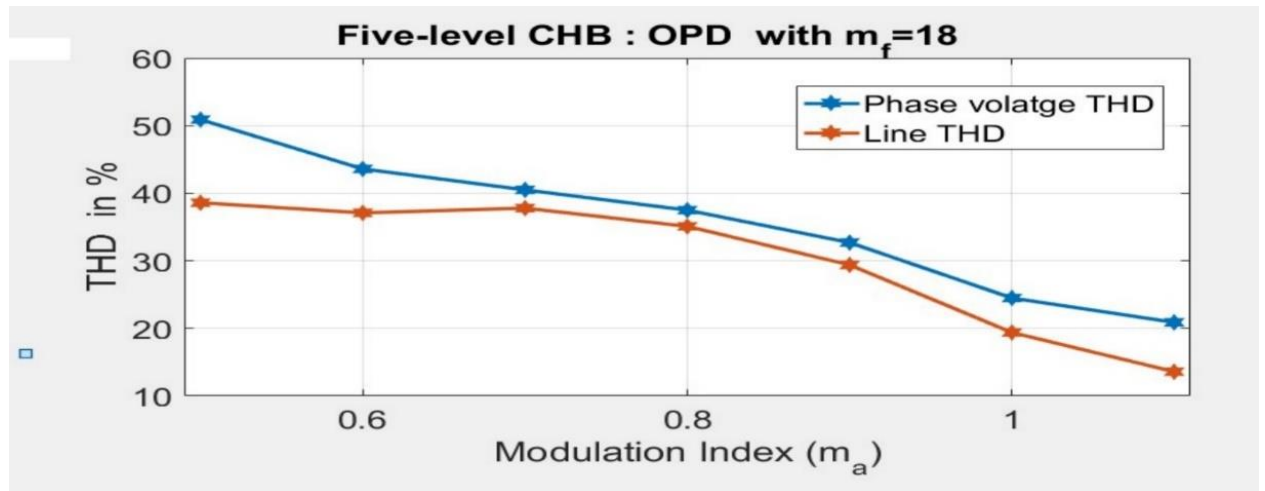

Figure 10: THD Performance of 5-Level CHB MLI IPD, f=900 Hz.
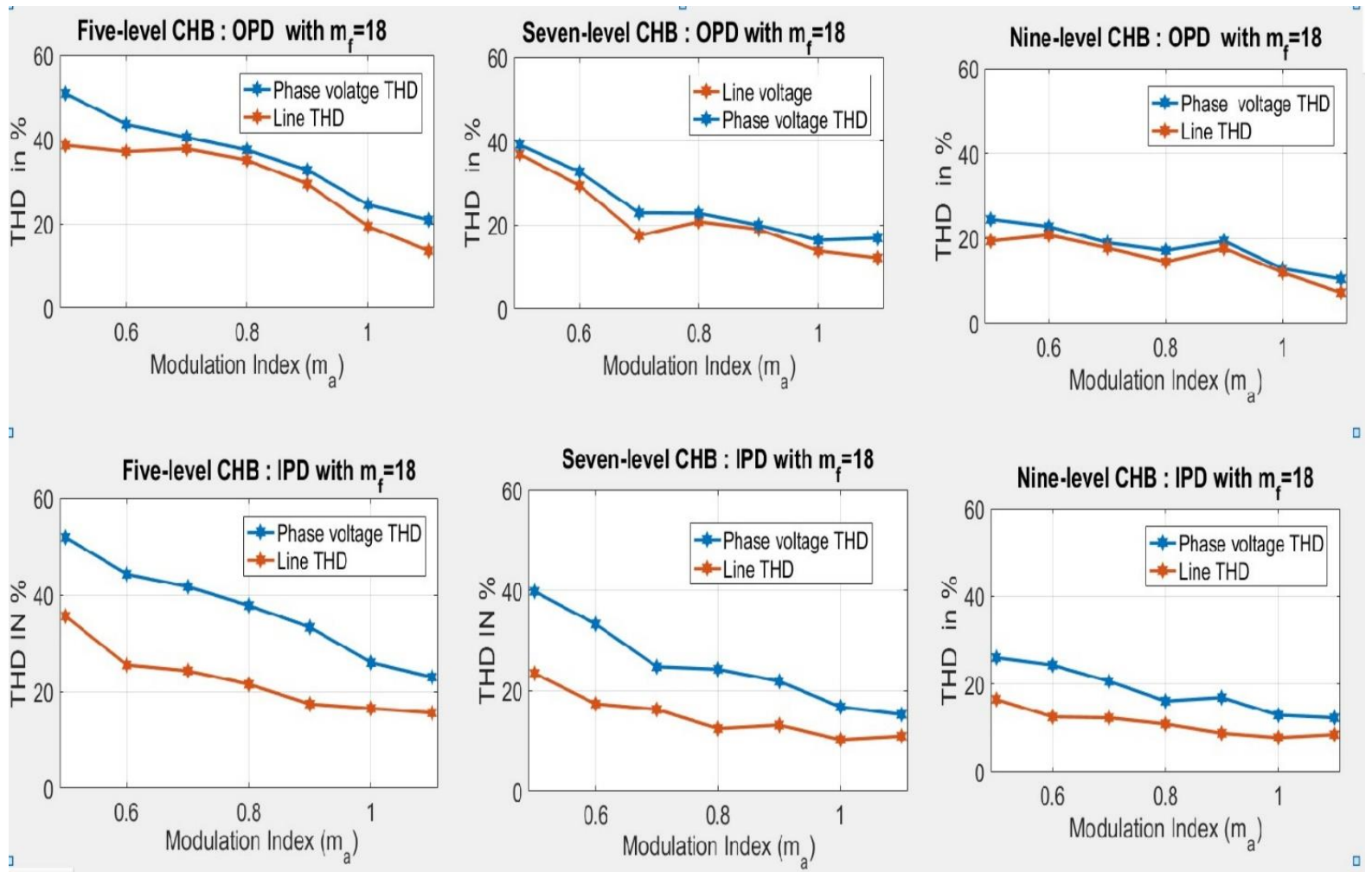

Figure 11: THD Performanceof 5, 7, 9 Levels CHB MLI IPD, Frequency $900 \mathrm{~Hz}$. 
In this way the THD performances are analyzed for 5-level, 7-level, 9-level CHB MLI with IPD, APD, OPD PWM techniques at various frequencies and for various ma values. It is observed that there is decrease in THD with the increase in the levels of the MLI.

The FFT analysis for different levels is shown below

- 5-level CHB MLI with OPD PWM technique

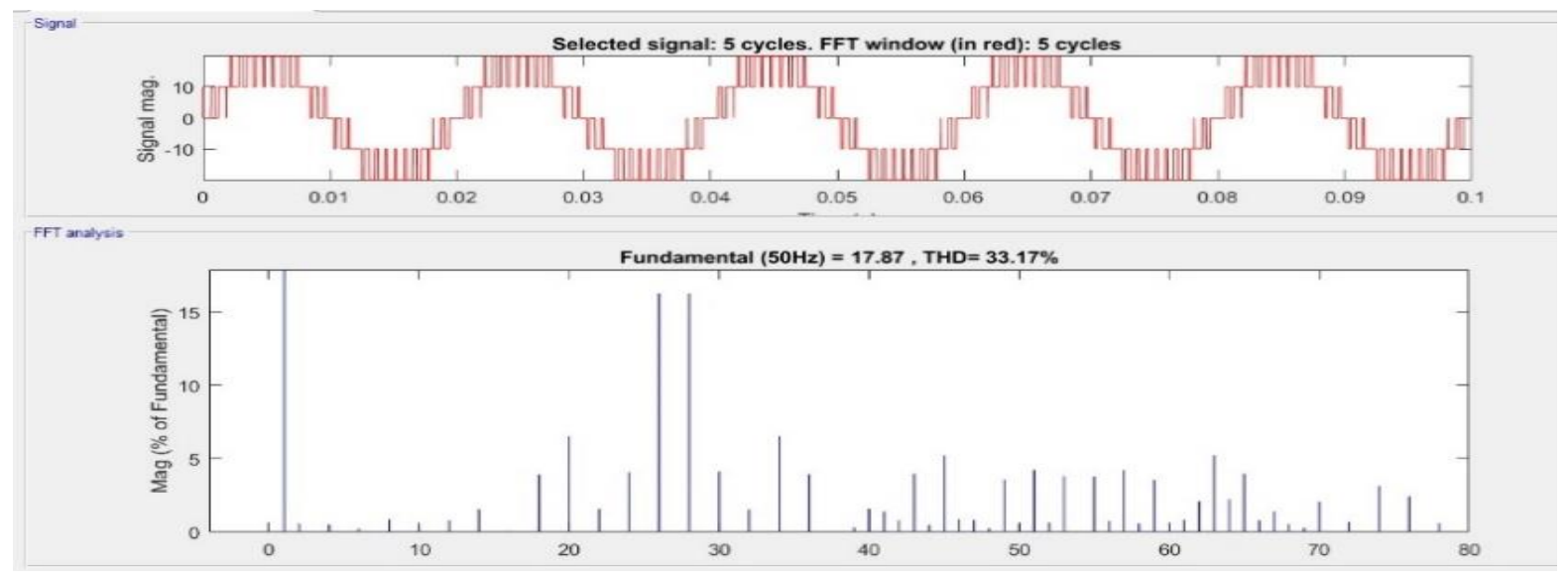

Figure 12: FFT Analysis of 3 Phase 5-Level CHBMLI with OPD PWM at $\mathrm{f}=1350$.

- 9-level CHB MLI with APD PWM technique

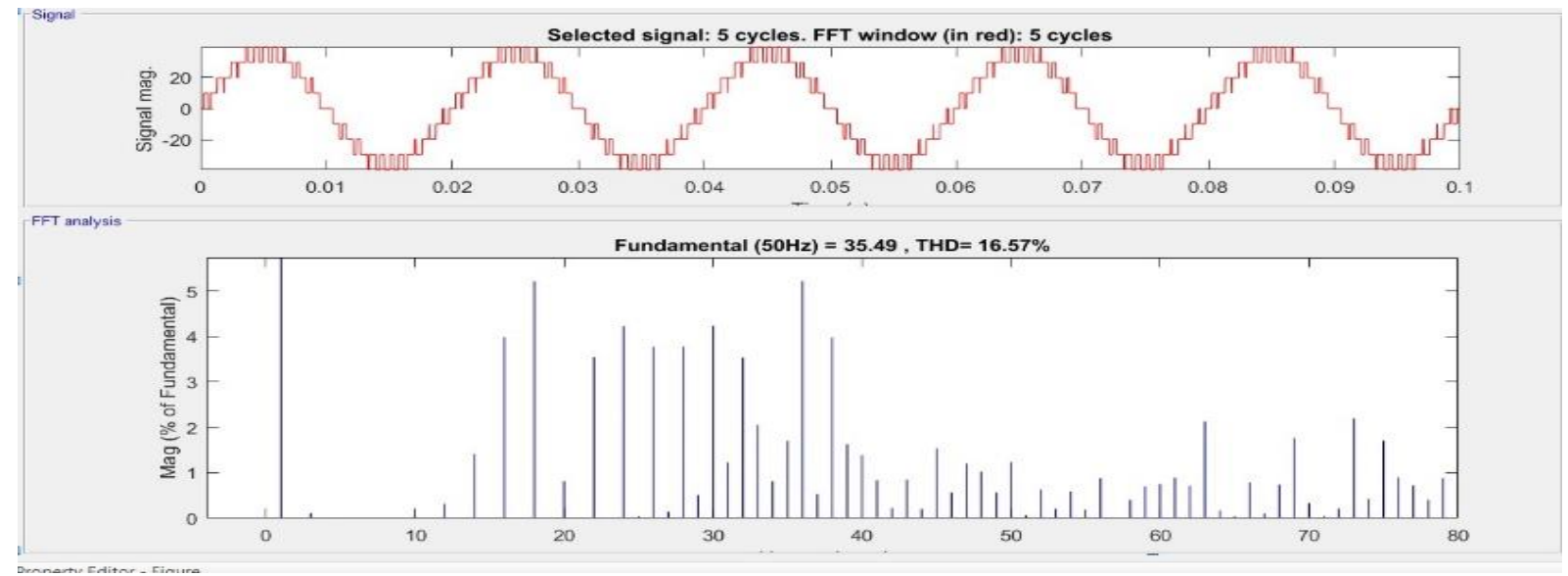

Figure 13: FFT Analysis of 3 Phase 9-Level CHB MLI with APD PWM at $\mathrm{f}=900$.

\section{CONCLUSIONS}

This paper reviews different types of control techniques and topologies of a multilevel inverter. The proposed system of CHB MLI uses the symmetrical topology with separate equal dc sources for the switching circuits. As voltage level increases, Less THD is seen at the voltage output, i.e. increase in step level decrease in harmonics at voltage output, and for a system of single-phase, all the LSPWM techniques can give satisfactory results i.e. low THD, but in a three-phase system compared to OPD and APD strategies, IPD PWM technique gives more satisfactory results for industrial applications,

The performance of the MLI with Fundamental and PWM switching schemes are studied through simulation (MATLAB SIMLINK). 
The components used in CHB MLI is less than other MLIs.CHB MLI's are used for applications of high voltages and currents which are useful for HEVs. It can be effectively used in industrial applications due to its low THD and in many applications like Energy storage, Grid connected-PV/Renewable system, Adjustable speed drives, Power quality (custom power devices), HVDC and Transportation applications, CHB MLI's when switched at low frequency, there will be low noise which can be supportive for driving HEVs.

\section{REFERENCES}

1. M. H. Rashid, "Power Electronics: Circuits, Devices and Applications", 3rd Edition, Pearson Education Inc, India, 2015.

2. E. Babaei, S. Alilu, S. Laali, "A new general topology for cascaded multilevel inverters with reduced number of components based on developed H-bridge", IEEE Trans. Ind. Electron., vol. 61, no. 8, pp. 3932-3939, 2014.

3. M. Aleenejad, H. Mahmoudi, R. Ahmadi, H. Iman-Eini, "A New High-Switching-Frequency Modulation Technique to Improve the DC-Link Voltage Utilization in Multilevel Converters", IEEE Transactions on Industrial Electronics, vol. 64, pp. 18071817, 2017.

4. Kiran, B. Madhu, and B V Sanker Ram. "Analysis of Cascaded H-Bridge Multilevel Inverter with Level Shifted PWM on Induction Motor."

5. R. S. Alishah, S. H. Hosseini, E. Babaei, M. Sabahi, "Optimization Assessment of a New Extended Multilevel Converter Topology", IEEE Transactions on Industrial Electronics, vol. 64, pp. 4530-4538, 2017.

6. Raghava, Jhv Veera, and K. Chandra Sekhar."Fault Analysis and Improvement of Power Quality Using 15 Level Cascaded Statcom. "International Journal of Electrical and Electronics Engineering Research (IJEEER) 3. 2, Jun 2013, 285-296

7. Chandramouli, A., Irfan, M.M. \& Yada, H.K. 2017, "Modeling and Simulation of Seven-Level Cascaded H-Bridge Inverter Based Shunt Active Power Filter for Single-Phase Distribution System", Proceedings - 2017 International Conference on Recent Trends in Electrical, Electronics and Computing Technologies, ICRTEECT 2017, pp. 101.

8. Kumar, B.J. \& Chandramouli, A. 2018, "Modeling and simulation of nine-level cascaded H-bridge inverter-based shunt active power filter for single-phase distribution system", Proceedings of the International Conference on Inventive Computing and Informatics, ICICI 2017, pp. 675.

9. Naveena, M., KB MadhuSahu, and Ch Krishna Rao. "16-cell back-to-back stacked multicell converter." ISSN (P).

10. Arulmurugan, R. \& Chandramouli, A. 2019, Modeling of PV powered seven-level inverter for power quality improvement.

11. Janardhan, Kavali, and Arvind Mittal. "Comparative Study of Various Cascaded H-Bridge Multilevel Inverter Topologies. "International Journal of Electrical and Electronics Engineering Research (IJEEER) 4. 3, Jun 2014, 51 -62

12. Chandramouli. A. \& Sivachiadambaranathan, V. 2019, "Design and analysis of a photovoltaic system with a DC-DC boost converter", Proceedings of the 3rd International Conference on Computing Methodologies and Communication, ICCMC 2019, pp.59 

